\title{
Effect of botulinum toxin A and nitroglycerin on random skin flap survival in rats
}

\author{
Kourosh Ghanbarzadeh MD ${ }^{1}$, Omid Reza Tabatabaie MD-MPH${ }^{2}$, Ebrahim Salehifar PharmD ${ }^{3}$, \\ Massoud Amanlou PharmD ${ }^{4}$, Ghasemali Khorasani MD ${ }^{1}$
}

\begin{abstract}
K Ghanbarzadeh, OR Tabatabaie, E Salehifar, M Amanlou, G Khorasani MD. Effect of botulinum toxin $\mathrm{A}$ and nitroglycerin on random skin flap survival in rats. Plast Surg 2016;24(2):99-102.
\end{abstract}

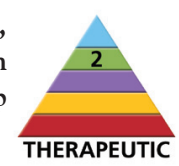

BACKGROUND: A suitable pharmacological substitute for the wellestablished surgical delay technique for random skin flaps to increase viability has been elusive.

OBJECTIVE: To evaluate the effects of nitroglycerin and botulinum toxin type A on random flap survival in a rat model.

METHODS: The present controlled experimental study was performed in the four groups of rats. One week after intervention in each group, the flap was raised and kept in situ, and flap necrosis was evaluated through followup. Group 1 received intradermal botulinum toxin type A (BTX-A) and topical nitroglycerin 2\%; group 2 received BTX-A and topical Vaseline (Unilever, USA); group 3 received topical nitroglycerin and intradermal normal saline; and group 4 received topical Vaseline and intradermal normal saline.

RESULTS: BTX-A reduced the area of necrosis compared with control ( $24 \%$ versus $56 \%$ respectively; $\mathrm{P}<0.001$ ). Nitroglycerin application was associated with a trend toward improved flap viability (42\% versus $56 \%$; $\mathrm{P}=0.059$ ). The combination of topical nitroglycerin and BTX-A, compared with Vaseline and BTX-A, was associated with decreased flap necrosis $(16.1 \%$ versus $24 \%$, respectively), although it was not statistically significant $(\mathrm{P}=0.45)$.

CONCLUSIONS: BTX-A was effective in reducing distal flap necrosis. The effect of BTX-A was significantly more pronounced than nitroglycerin ointment.

Key Words: Botulinum toxin type A; Flap; Nitroglycerin; Rat; Skin flap

\section{L'effet de la toxine botulique de type A et de la nitroglycérine sur la survie de lambeaux cutanés sans dissection pédiculaire chez des rats}

HISTORIQUE : Il n'existe aucun substitut pharmacologique convenable pour remplacer la technique d'autonomisation bien établie visant à accrô̂tre la survie des lambeaux cutanés.

OBJECTIF : Évaluer les effets de la nitroglycérine et de la toxine botulique de type A (BTX-A) sur la survie de lambeaux sans dissection pédiculaire dans un modèle de rat.

MÉTHODOLOGIE : Les chercheurs ont réalisé la présente étude expérimentale contrôlée auprès de quatre groupes de rats. Dans chaque groupe, une semaine après l'intervention, ils ont prélevé le lambeau et l'ont conservé in situ, puis ont évalué la nécrose du lambeau au suivi. Le groupe 1 a reçu de la BTX-A par voie intradermique et de la nitroglycérine topique $2 \%$. Le groupe 2 a reçu de la BTX-A et de la Vaseline topique (Unilever, ÉtatsUnis). Le groupe 3 a reçu de la nitroglycérine topique et un soluté physiologique par voie intradermique. Enfin, le groupe 4 a reçu de la Vaseline topique et un soluté physiologique par voie intradermique.

RÉSULTATS : La BTX-A réduisait l'aire de la nécrose par rapport à celle des sujets témoins ( $24 \%$ au lieu de $56 \%$, respectivement; $\mathrm{P}<0,001$ ). L'application de nitroglycérine favorisait une meilleure viabilité du lambeau $(42 \%$ par rapport à $56 \% ; \mathrm{P}=0,059)$. Par rapport à la Vaseline et à la BTX-A, la combinaison de nitroglycérine topique et de BTX-A s'associait à une diminution de la nécrose du lambeau $(16,1 \%$ au lieu de $24 \%)$, même si ce n'était pas statistiquement significatif $(\mathrm{P}=0,45)$.

CONCLUSIONS : La BTX-A a réussi à réduire la nécrose du lambeau distal. Elle avait beaucoup plus d'effet que l'onguent de nitroglycérine.

$T_{1}$ he random skin flap (RSF) is a type of flap that has no discrete blood vessels. Consequently, RSFs are dependent on different microvascular plexuses for their metabolic needs; thus, RSFs are prone to ischemic injury (1). In normal conditions, skin blood flow is mainly regulated by the neural input; however, in the case of a skin flap, humoral vasoactive substances, such as nitric oxide (NO), also play an important role (2). In the immediate aftermath of flap elevation, local loss of sympathetic input, coupled with the unchallenged activity of humoral vasoconstrictors, leads to an ischemic state in RSFs, which is most pronounced during the first $6 \mathrm{~h}$ to $12 \mathrm{~h}$ postoperatively (3). This ischemic state is normally reversed after day 3 . However, if necrosis follows the ischemic insult, the process would be irreversible and flap failure ensues. Such a scenario is encountered especially when the length-to-width ratio of the RSF is increased (2-4). Based on the donor site, RSFs with length-to-width ratios $>2: 1$ to 3:1 will usually fail to some extent due to ischemia in the absence of additional interventions such as delay procedures (5).

Delay techniques are devised to facilitate the adaptation of the RSFs to the ischemic environment. Surgical delay procedures are currently the gold standard for such techniques; however, they have some drawbacks. Notably, $\geq 1$ surgical stage(s) are needed before the main procedure can be performed (6).

Many pharmacological and physical therapies have been investigated to mimic the effects of surgical delay. Some agents have shown promising results in RSFs and other types of skin flaps, as well as in ischemic conditions such as chronic anal fissure. Experiments using botulinum toxin type A (BTX-A) and NO donors, such as nitroglycerin, resulted in interesting outcomes in a variety of ischemic conditions such as RSFs and chronic anal fissures $(2,7,8)$. Furthermore, one study reported a synergistic effect between BTX-A and nitroglycerin in chronic anal fissure, which is a well established ischemic condition (9).

Although ischemia is also considered to be the pathophysiological process in the failure of RSFs, no study has investigated a possible synergistic or additive effect between BTX-A and nitroglycerin in this regard. Therefore, the purpose of the present study was to investigate the effects of nitroglycerin, BTX-A and their combination on the survival of RSFs.

Drugs

\section{METHODS}

Drugs used in the present study included nitroglycerine $2 \%$ ointment (Myovin, Cadila Cooperation, India), BTX-A (Dysport, Epsen Pharmaceuticals, United Kingdom), ketamine hydrochloride

${ }^{1}$ Division of Plastic and Reconstructive Surgery, Imam Khomeini Hospital Complex; ${ }^{2}$ Tehran University of Medical Sciences, Tehran; ${ }^{3}$ Department of Clinical Pharmacy, Faculty of Pharmacy, Mazandaran University of Medical Sciences, Sari; ${ }^{4}$ Department of Medical Chemistry, Faculty of Pharmacy, Tehran University of Medical Sciences, Tehran, Iran

Correspondence: Dr Ghasemali Khorasani, Division of Plastic and Reconstructive Surgery, Imam Khomeini Hospital Complex, Tehran University of Medical Sciences, Tehran, Iran. Telephone 00982122264626, fax 0098216643815, e-mail gakhorasani@yahoo.com 
TABLE 1

\section{Study groups}

\begin{tabular}{lcc}
\hline Group & Drug 1 (injection) & Drug 2 (ointment) \\
\hline 1 & Botulinum toxin type A & Nitroglycerine \\
2 & Botulinum toxin type A & Vaseline* \\
3 & Saline & Nitroglycerine \\
4 & Saline & Vaseline* $^{*}$ \\
\hline
\end{tabular}

*Unilever, USA

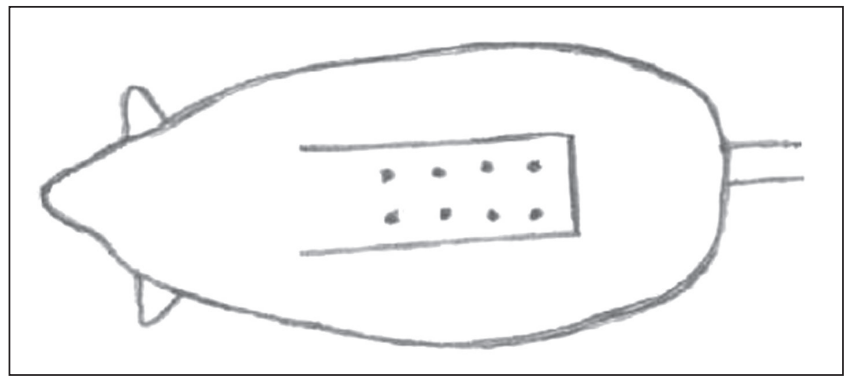

Figure 1) Injection sites of botulinum toxin type A and design of flap

(Gedoon Richter Ltd, Hungary) and xylazine hydrochloride (BayerAG, Germany).

\section{Animals}

Seventy-two Wistar rats weighing $250 \mathrm{~g}$ to $300 \mathrm{~g}$ were randomly allocated to four study groups. The animals were provided by the Faculty of Pharmacy, Tehran University of Medical Sciences (Tehran, Iran). A $12 \mathrm{~h}$ light-dark cycle was implemented and the animals had unlimited access to food and water throughout the experiment. The study was approved by the Ethics Committee of Tehran University of Medical Sciences, and national and institutional guidelines for laboratory animal care were followed regarding all animal procedures. The experiments were performed in the Faculty of Pharmacy, Tehran University of Medical sciences during December 2013.

\section{Study design}

Four groups were designated and 18 rats were allocated to each using a block randomization method. The study groups are summarized in Table 1. Each rat was given an injection and an ointment. The animal laboratory technician who performed the experiments was not informed about the content of each syringe (BTX-A or normal saline) or ointment tube (nitroglycerin or petroleum jelly [Vaseline, Unilever, USA]).

Rats in groups 1 and 2 were given 24 IU/kg of BTX-A via intradermal injection two weeks before the surgery $(0.25 \mathrm{~mL}$ to $0.3 \mathrm{~mL}$ of $500 \mathrm{IU}$ vial diluted in $20.8 \mathrm{~mL} 0.9 \%$ saline). The rats in groups 3 and 4 were injected with an equal volume of $0.9 \%$ saline solution. The dose was divided and injected at eight sites on the predefined future flap (Figure 1).

Topical 2\% nitroglycerin ointment ( 0.5 inch) was applied over the base of the flap just before the surgery followed by daily administration until postoperative day 5 (groups 1 and 3). The rats in groups 2 and 4 were given an equal amount of vaseline ointments.

\section{Procedure}

Intraperitoneal injection of ketamine $(90 \mathrm{mg} / \mathrm{kg})$ and xylazine $(9 \mathrm{mg} / \mathrm{kg})$ was used for anesthesia. Additional ketamine doses were administered for the maintenance of anesthesia as needed. A $10 \mathrm{~cm} \times 3 \mathrm{~cm}$ cranially based random flap including the panniculus carnosus was raised completely and then sutured back to its primary site using $5 / 0$ nylon sutures as described previously (3). Any residual perforating vessel was severed to ensure adequate technique.

\section{Measurement and analysis}

The rats were euthanized using chloroform on the postoperative day 7 . Necrosis area was considered to be the primary outcome. A researcher,
TABLE 2

Necrosis area in each experimental group

\begin{tabular}{lcc}
\hline & \multicolumn{2}{c}{ Area } \\
\cline { 2 - 3 } Group $^{*}$ & Necrosis, $\mathbf{~ m m}^{\mathbf{2}}$, mean $\mathbf{\text { SD }}$ & Percentage \\
\hline 1 & $484 \pm 303$ & 16.1 \\
2 & $726 \pm 291$ & 24 \\
3 & $1267 \pm 593$ & 42 \\
4 & $1685 \pm 634$ & 56 \\
\hline
\end{tabular}

*Group 1 (intradermal botulinum toxin type $A[B T X-A]$ and $2 \%$ topical nitroglycerin ointment); group 2 (BTX-A with Vaseline [Unilever, USA]); group 3 (nitroglycerin ointment with normal saline); group 4 (Vaseline with normal saline)

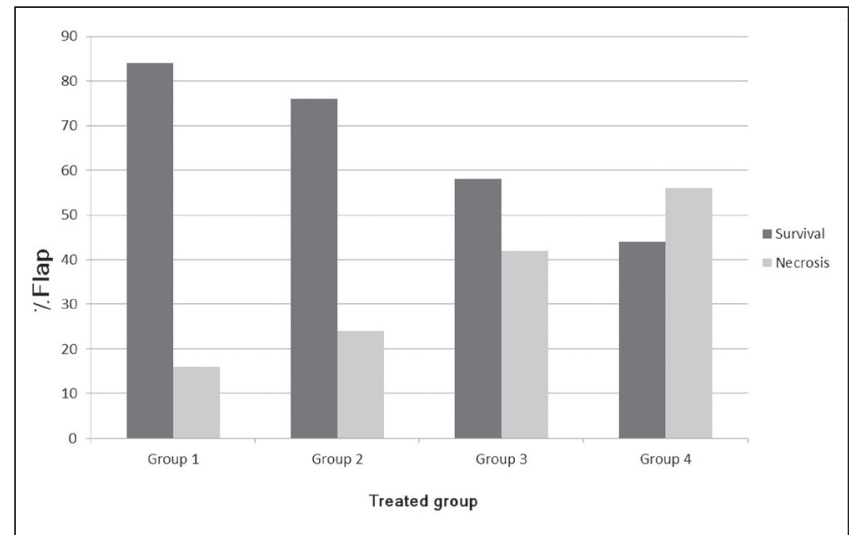

Figure 2) Necrosis to total flap area from different groups. Group 1 (intradermal application of botulinum toxin type A [BTX-A] and topical ointment of nitroglycerin 2\%); group 2 (BTX-A with Vaseline [Unilever, USA]); group 3 (nitroglycerin ointment with normal saline); and group 4 (Vaseline with normal saline)

who was blinded to treatment, examined the rats for necrosis area based on gross pathological appearance. Necrosis area was marked on a predefined transparent template that was placed on the flap templates, were then scanned and necrosis area was calculated electronically using an image analysis system (M2 Image Analysis System, Imaging Research, Inc, Canada) (10).

ANOVA was performed to compare the mean necrosis areas among the different study groups. Tukey's B post hoc test was implemented to compare the mean difference of necrosis area among the study groups. SPSS version 15.0 (IBM Corporation, USA) was used to analyze the data.

\section{RESULTS}

Two rats died during the study (one rat in group 2, one in group 4), the data from which were excluded from the analysis. Necrosis was observed in all of the flaps except for two in group 1 . Necrosis area and percentage in each group are summarized in Table 2 and Figure 2. Figure 3 depicts the gross appearance of the flaps on postoperative day 7 . Comparison of necrosis area in the different groups is summarized in Table 3.

BTX-A significantly reduced distal flap necrosis compared with controls $(\mathrm{P}<0.001)$. Nitroglycerine use was also associated with decreased distal necrosis area; however, it only approached statistical significance ( $42 \%$ versus $56 \%$, respectively; $\mathrm{P}=0.059$ ). Furthermore, BTX-A injection was significantly more effective than topical application of $2 \%$ ointment of nitroglycerin in reducing flap necrosis $(\mathrm{P}=0.008)$. Addition of nitroglycerin to BTX-A did not significantly improve the effects of BTX-A $(\mathrm{P}=0.455)$.

\section{DISCUSSION}

Traditionally, surgical delay has been used to prevent necrosis of larger flaps. Surgical delay is believed to enhance flap survival mainly via two ischemia-related mechanisms: durable vasodilation and angiogenesis (4). Efforts have been made to use vasoactive agents such as nitroglycerine 


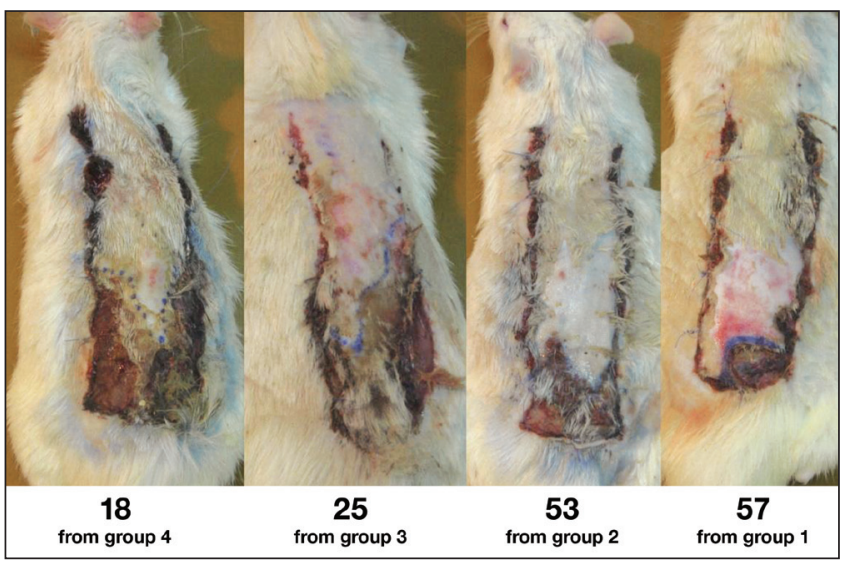

Figure 3) Representative photograph of flaps from each group. Group 1 (intradermal application of Botulinum toxin type A [BTX-A] and topical ointment of nitroglycerin 2\%]); group 2 (BTX-A with Vaseline [Unilever, USA]); group 3 (nitroglycerin ointment with normal saline); group 4( (Vaseline with normal saline)

and BTX-A instead of surgical delay, which is time consuming and labour intensive.

The role of NO in flap survival has been extensively studied. NO is known to be a potent vasodilator as well as an agent with pro-angiogenic, antiplatelet and antioxidative properties. Nitroglycerine is a well-known $\mathrm{NO}$ donor that exerts its effects mainly via vasodilation $(4,11)$. Furthermore, NO donors, especially nitroglycerine, have been studied in other ischemic conditions, notably chronic anal fissure with promising results $(12,13)$.

BTX-A is the longest-acting toxin derived from the bacterium Clostridium botulinum. It has gained popularity in a variety of applications and conditions, both ischemic and nonischemic. BTX-A consists of a light chain and a heavy chain, which is responsible for most of its pharmacological actions. BTX-A has strong vasodilatory effects exerted by different mechanisms mainly via blockade of cholinergic neurotransmitter release. SNAP-25 is a SNARE protein responsible for neurotransmitter release. BTX-A inhibits cholinergic neurotransmitter release by proteolysis of SNAP-25 among other SNARES (14). Furthermore, BTX-A interacts with the Rho/Rho kinase system and, by interfering with $\mathrm{Ca}^{2+}$ influx, causes smooth muscle relaxation in vessel walls. Schweizer et al (15) reported an increase in flap blood flow and survival by this mechanism. Kim et al (2) proposed a sympatholytic mechanism for BTX-A, and reported an increased survival of random flaps in rats using BTX-A by $8.3 \%$. Arnold et al (10) proposed that BTX-A improves flap survival on account of its antiinflammatory and vasoactive effects.

While nitroglycerine and BTX-A both have established vasodilatory effects in skin flaps, their mechanism of action is different and, thus, an additive action is probable. Complementary additive action exists when two drugs act on different pathways leading to one end result (16). In the case of BTX-A and nitroglycerin, such action may exist because different pathways are targeted by these drugs with the end result being vasodilation. This hypothesis has been previously tested in chronic anal fissure with success. Lysy et al (9) reported a synergistic effect between nitroglycerin and BTX-A in anal fissure treatment (9).

To our knowledge, the present study was the first to simultaneously evaluate the effects of nitroglycerin and BTX-A on RSF viability in rats for possible additive effects. The present study showed that administration of BTX-A significantly decreases RSF necrosis in rats. This is in accordance with other recent studies $(2,17)$. Kim et al (17) reported increased survival of dorsal random flaps in rats using BTX-A.

The present study demonstrated a beneficial trend for nitroglycerin in improving RSF survival in rats with marginal statistical significance. However, our results show that nitroglycerin ointment
TABLE 3

Comparison of necrosis area among the different groups

\begin{tabular}{lccrcr}
\hline Group (I) & $\begin{array}{c}\text { Comparator } \\
\text { (J) }\end{array}$ & $\begin{array}{c}\text { Mean difference } \\
\text { (I-J), } \mathbf{~ m m}^{2} \text { (\%) }\end{array}$ & SE & $\begin{array}{r}\text { 95\% Cl of } \\
\text { difference }\end{array}$ & \multicolumn{1}{c}{ P } \\
\hline Group 1 & Group 2 & $241(8)$ & 163 & -188 to 671 & 0.455 \\
Group 1 & Group 3 & $782(26)^{*}$ & 160 & 358 to 1205 & $<0.001$ \\
Group 1 & Group 4 & $1201(40)^{*}$ & 163 & 771 to 1630 & $<0.001$ \\
Group 2 & Group 3 & $540(18)^{*}$ & 163 & 111 to 970 & 0.008 \\
Group 2 & Group 4 & $959(32)^{*}$ & 165 & 524 to 1395 & $<0.001$ \\
Group 3 & Group 4 & $419(14)$ & 163 & -10 to 848 & 0.059 \\
\hline
\end{tabular}

${ }^{*}$ Mean difference of necrosis area was considered to be statistically significant at $P<0.05$. Group 1 (intradermal botulinum toxin type $A[B T X-A]$ and $2 \%$ topical nitroglycerin ointment); group 2 (BTX-A with Vaseline [Unilever, USA]); group 3 (nitroglycerin ointment with normal saline); group 4 (Vaseline with normal saline). SE Standard error

is inferior to BTX-A in decreasing RSF necrosis in rats. Although no study has simultaneously compared the two in RSFs, there are a few reports of inadequate response to nitroglycerin ointment $(1,18)$.

Addition of nitroglycerin to BTX-A resulted in an $8 \%$ decrease of necrosis area compared with BTX-A alone (Table 2); however, the effect was not statistically significant. This may be due to low bioavailability of daily administration of topical nitroglycerin ointment in ischemic flaps or its low $\mathrm{NO}$ donation potency. It must be noted that $\mathrm{NO}$ metabolism is complex and different $\mathrm{NO}$ donors have been reported to have different potentials in ischemic lesions $(4,11)$. It is also possible that high doses of BTX-A, which were used in the present study, achieved full vasodilatory potential, leaving no opportunity for nitroglycerin to exert its vasodilatory effects. Subtherapeutic doses of BTX-A should be used in future studies with increasing doses of nitroglycerin or other $\mathrm{NO}$ donors to better elucidate possible interactions.

\section{CONCLUSIONS}

BTX-A was effective in reducing distal flap necrosis area and there was a trend toward efficacy for nitroglycerin. The effect of BTX-A was significantly better than nitroglycerin ointment.

ACKNOWLEDGEMENT: This work was supported by a grant (Grant number 11193) from Tehran University of Medical Sciences, Iran.

DISCLOSURES: The authors have no finanacial disclosures or conflicts of interest to declare.

\section{REFERENCES}

1. Atalay C, Kockaya EA, Cetin B, Kismet K, Akay MT. Efficacy of topical nitroglycerin and transcutaneous electrical nerve stimulation on survival of random-pattern skin flaps in rats. Scand J Plast Reconstr Hand Surg 2003;37:10-3.

2. Kim TK, Oh EJ, Chung JY, Park JW, Cho BC, Chung HY. The effects of botulinum toxin $\mathrm{A}$ on the survival of a random cutaneous flap. J Plast Reconstr Aesth Surg 2009;62:906-13.

3. Taleb S, Moghaddas P, Rahimi Balaei M, et al. Metformin improves skin flap survival through nitric oxide system. J Surg Res 2014192:686-91.

4. Topp SG, Zhang F, Chatterjee T, Lineaweaver WC. Role of nitric oxide in surgical flap survival. J Am Coll Surg 2005;201:628-39.

5. Pang CY, Forrest CR, Morris SF. Pharmacological augmentation of skin flap viability: A hypothesis to mimic the surgical delay phenomenon or a wishful thought. Ann Plast Surg 1989;22:293-306.

6. Reichenberger MA, Keil H, Mueller W, et al. Comparison of extracorporal shock wave pretreatment to classic surgical delay in a random pattern skin flap model. Plast Reconstr Surg 2011;127:1830-7.

7. Waters LM, Pearl RM, Macaulay RM. A comparative analysis of the ability of five classes of pharmacological agents to augment skin flap survival in various models and species: An attempt to standardize skin flap research. Ann Plast Surg 1989;23:117-22. 
8. Brisinda G, Cadeddu F, Brandara F, Marniga G, Maria G. Randomized clinical trial comparing botulinum toxin injections with 0.2 per cent nitroglycerin ointment for chronic anal fissure. $\mathrm{Br}$ J Surg 2007;94:162-7.

9. Lysy J, Israelit-Yatzkan Y, Sestiery-Ittah M, Weksler-Zangen S, Keret D, Goldin E. Topical nitrates potentiate the effect of botulinum toxin in the treatment of patients with refractory anal fissure. Gut 2001;48:221-4.

10. Arnold PB, Fang T, Songcharoen SJ, Ziakas G, Zhang F. Inflammatory response and survival of pedicled abdominal flaps in a rat model after perivascular application of botulinum toxin type a. Plast Reconstr Surg 2014;133:491e-8e.

11. Munzel T, Daiber A, Gori T. More answers to the still unresolved question of nitrate tolerance. Eur Heart J 2013;34:2666-73.

12. Altomare DF, Rinaldi M, Milito G, et al. Glyceryl trinitrate for chronic anal fissure - healing or headache? Results of a multicenter, randomized, placebo-controled, double-blind trial. Dis Colon Rectum 2000;43:174-9.

13. Gorfine SR. Topical nitroglycerin therapy for anal fissures and ulcers. N Engl J Med 1995;333:1156-7.
14. Foran PG, Mohammed N, Lisk GO, et al. Evaluation of the therapeutic usefulness of botulinum neurotoxin $\mathrm{B}, \mathrm{C1}, \mathrm{E}$, and $\mathrm{F}$ compared with the long lasting type A. Basis for distinct durations of inhibition of exocytosis in central neurons. J Biol Chem 2003;278:1363-71.

15. Schweizer DF, Schweizer R, Zhang S, et al. Botulinum toxin A and $\mathrm{B}$ raise blood flow and increase survival of critically ischemic skin flaps. J Surg Res 2013;184:1205-13.

16. Jia J, Zhu F, Ma X, Cao ZW, Li YX, Chen YZ. Mechanisms of drug combinations: Interaction and network perspectives. Nat Rev Drug Discov 2009;8:111-28.

17. Kim YS, Roh TS, Lee WJ, Yoo WM, Tark KC. The effect of botulinum toxin A on skin flap survival in rats. Wound Repair Regen 2009;17:411-7.

18. Sa JZ, Aguiar JL, Cruz AF, Schuler AR, Lima JR, Marques OM. The effects of local nitroglycerin on the surgical delay procedure in prefabricated flaps by vascular implant in rats. Acta Cir Bras 2012;27:905-11. 